\section{MANAGEMENT OF SINUS DUE TO NECROSIS OF RIGHT TRANSVERSE PROCESS OF SECOND LUMBAR VERTEBRA IN AN ELEPHANT}

\author{
S.K. Pandey \\ Professor and Head, Department of Surgery and Radiology, \\ Veterinary College, Jabalpur, Madhya Pradesh, India.
}

Even though domestication of elephants for private or community use was in vogue since early days, incidences of fractures and fracture-related complications in elephants were not well documented (Schmidt, 1978). This note reports a case of a sinus due to fracture of right transverse process of second lumbar vertebra.

A male elephant aged about 15 years (height: 8' 6") had a history of swelling and subsequent drainage of pus from the lumbar area whenever the howdah was seated for a long time. However, the discharge decreased or even disappeared whenever the animal was given rest and the howdah was removed. Clinical examination revealed cicatrised spots and probing indicated the depth of sinus to be nearly $10 \mathrm{~cm}$. The discharge was foetid and sanguinous (Fig. 1). It was decided to open the sinus to remove the necrotic tissues and provide free drainage.

The animal was given $300 \mathrm{mg}$. of xylazine intramuscularly and it went to lateral recumbency after 15 minutes. The area extending from last thoracic to $4^{\text {th }}$ lumbar vertebra was then cleaned with soap and water and Tr. Iodine was applied. A 12 $\mathrm{cm}$. long fish head probe was introduced through the opening and directed downwards and forwards to reach the depth of the sinus. The sinus was then opened to its entire length and depth with the help of a knife. The entire sinus tract was filled with reddish exudate containing necrotic tissue. Exploration of the base of sinus cavity indicated the involvement of right transverse process of second lumbar vertebra towards its summit. The necrosed part of transverse process was then removed.

A $12 \mathrm{~cm}$. long longitudinal incision was made dividing the longismus dorsi muscle on the right side and exposing the vertebrae. The affected transverse process was made free from the surrounding tissues and an embryotomy wire was passed beneath it. The necrosed part of transverse process was separated including a portion of normal bone by moving the wire in sawing motion. The debridgement was done with the help of scissors to make the area free from necrosed tissues. The wound was then cleaned with $4 \%$ Chlorhexidine solution and painted with Providone iodine solution. Tetracycline $(30 \mathrm{ml} \mathrm{i} / \mathrm{m}$.) was given for eight days. Cleaning of wound with Chlorhexidine and painting with Providone iodine was continued. It took nearly three months for the wound to heal. The animal was put to work after four months from the date of operation. Reappearance was not reported even after six months of regular service.

The deprivation of blood supply to a portion of bone can result in loss of vitality of the affected part. Subsequent bacterial infection can lead to suppuration and drainage from the affected part. In the present case it seems that the second lumbar vertebra might have been under pressure due to the faulty fitting of the howdah. This in turn might have resulted in excessive pressure on the right side, specifically on the lumbar vertebrae, leading to interference in the blood supply and subsequent pressure necrosis.

The entrance of alien organisms apparently caused sepsis. The removal of necrosed bone, effective surgical drainage and antibacterial therapy proved effective in treating the sinus.

\section{Reference}

Schmidt, M. (1978). Zoo and Wild Animal Medicine. W.B. Saunders Co. Philadelphia, London.

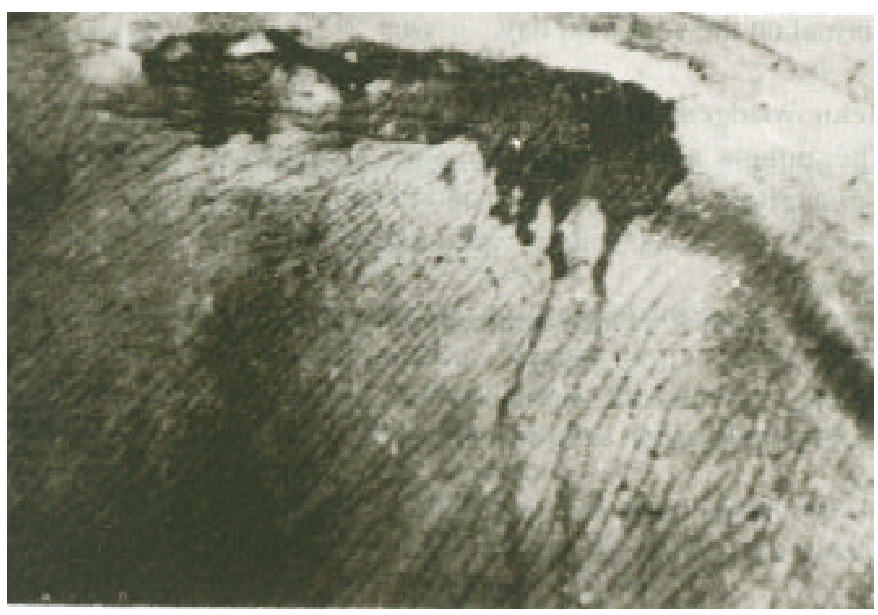

Figure 1. Draining sinus due to fracture of transverse process of lumbar vertebrae in an elephant. 